\title{
Performance Evaluation of a Hybrid Solar Collector in Two Different Climates
}

\author{
Ahssan M. A. Alshibil, Piroska Víg, and Istvan Farkas
}

\section{ABSTRACT}

The solar hybrid collector (PV/T) modules are a beneficial approach that simultaneously transforms solar radiation into heat and electric power. This work examined the performance of a PV/T module with flat-plate absorber type and water-cooled by optimizing the PV/T model under two significantly different climate conditions. The first is for Stuttgart city, and the second is for Kabul. According to what has been conducted in this study, Kabul has a higher percentage of the received heat energy than Stuttgart, at more than $50.4 \%$. Furthermore, Kabul's electrical efficiency is $48.3 \%$ higher than Stuttgart's. As a matter of fact, the annual radiation of Kabul is more than Stuttgart city by $\mathbf{4 9 . 1 2 \%}$. Thus, Kabul city seems to be more convenient than Stuttgart for the PV/T applications.

Keywords: Climates, performance evaluation, PV/T collector.
Published Online: June 30, 2020

ISSN: $2736-5506$

DOI : $10.24018 /$ ejenergy.2021.1.2.11

\section{Ahssan M.A. Alshibil*}

Doctoral School of Mechanical Engineering, Hungarian University of Agriculture and Life Sciences, Godollo, Hungary.

Department of Mechanical Engineering, College of Engineering, University of Kufa, Iraq.

(e-mail:

Al.Shibil.Ahssan.Mohamed.Ali.Kare m@phd.uni-szie.hu)

Piroska Víg

Institute of Mathematics and Basic Science, Hungarian University of Agriculture and Life Sciences, Godollo, Hungary.

(e-mail: Vig.Piroska@uni-mate.hu) Istvan Farkas

Institute of Technology, Hungarian

University of Agriculture and Life

Sciences,

Godollo, Hungary.

(e-mail: Farkas.Istvan@uni-mate.hu)

*Corresponding Author

\section{INTRODUCTION}

Thermal and electrical energies might be extracted with the use of solar photovoltaic (PV) and thermal (T) receivers via hybrid solar collector PV/T at the same time. The PV/T system combination includes a PV module and a heat exchanger behind it. The fluid used for cooling is distributed in the heat exchanger. Water and air are the most common fluids [1], [2].

In order to assess the efficiency of various semiconductors, Badescu et al. [3] implemented a new technique on PV/T as solar converters. In case of normal silicon semiconductor they observed $70 \%$ and $20 \%$ of the optimum thermal and electrical efficiencies. These findings demonstrated that photovoltaic material is suitable for $\mathrm{PV} / \mathrm{T}$.

In terms of determining the transient potential of the PV/T collector using one and two glass designs, Garg and Adhikar [4] have created a simulation model. They noted the considerable dependence of power on the airflow rates and reduction with the rise in the air temperature on the power generation of the PV/T.
Tiwari and Sodha [5] noted that at low temperatures the glass cover PV/T air collector had greater conversion performance than that without glass cover.

The output of a PVT collector is influenced to different levels by construction, climatic, and operating conditions [6], [7]. In recent years, PV/T systems and their utilizes in different climatic circumstances have been of interest to researchers with several studies on this topic [8].

As a function of climatic conditions and configurations, Dubey et al. [9] developed the utility performance of PV/T air collectors based on PV position either between two glasses or between glass and Tedlar. The results report that the twoglass case has more efficiency instead of the other cases. In their in-depth study, Joshi et al. [10] examined a PV/T module for the Indian region's climatic requirements theoretically and conducted an experimental validation. It is found that the PV/T without the Tedlar layer has more thermal efficiency.

Kumer and Rosen [11] comprehensively presented an analysis to study the influence of climate, configuration, operating condition, and performance behavior of the PV/T system. Cell temperature decreasing is confirmed by $19.5 \%$ 
for the lower fins type. Besides, Fábio et al. [12] indicated that the temperatures being directly proportional to the radiation.

Theoretically, this work examined the performance of the $\mathrm{PV} / \mathrm{T}$ module with flat-plate absorber type and water-cooled by optimizing the PV/T model under two different climate conditions. The first is in Stuttgart, Europe and the second is in Kabul, Asia.

The performance comparison holds to investigate the PV/T results for both locations. With recently reported findings, the established model is tested. The proposed system was used to compare the performance of $\mathrm{PV} / \mathrm{T}$ in the two locations under the standard pattern of the common program in modeling solar systems (TRNSYS).

\section{WATER-BASED PV/T EVALUATION SYSTEM}

The investigation system in this study has been presented as in Fig. 1. A water-cooled PV/T module, a tank for hot water storage, the water pump, and the temperature controller are the system's main components.

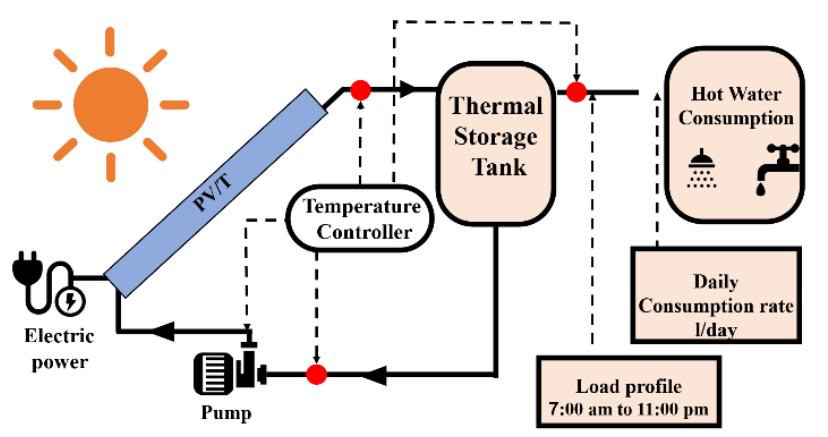

Fig. 1. Photovoltaic/thermal system.

As an assumption in this study, the volume of the hot water storage tank is $0.5 \mathrm{~m}^{3}$. The use of hot water is not constant, and it depends on which applications will be used and how many people consume the hot water.

As an example of the consumer's habit, the rate of daily consumption of water is 150 litres. It is used from 7:00 a.m. to $11: 00$ p.m. at regular intervals supposing the profile as shown in Fig. 2.

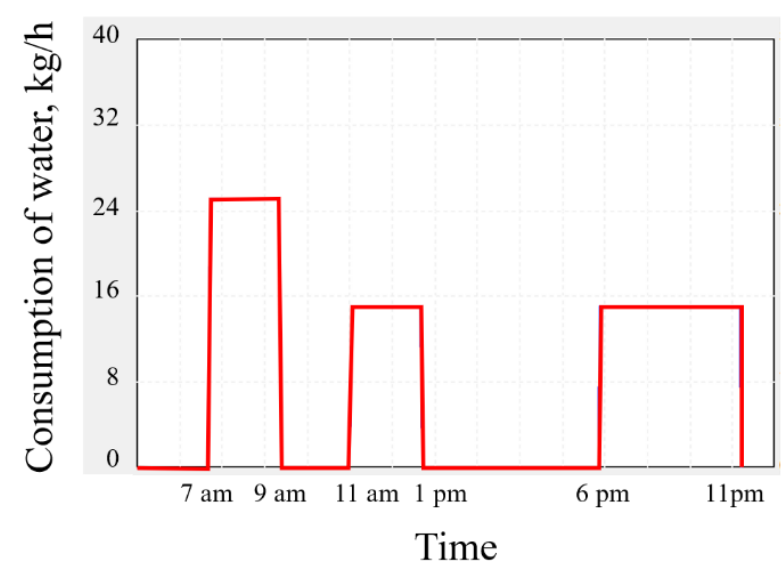

Fig. 2. Profile of water use.

\section{Modelling Results}

The proposed system was used to compare two locations in different weather conditions within the common program in modelling solar systems (TRNSYS). The first is in Europe, Stuttgart, and the second is in Asia, Kabul.

The developed TRNSYS model for the proposed system is shown in Fig. 3. It contains the main components that need to run the simulation process in the TRNSYS software.

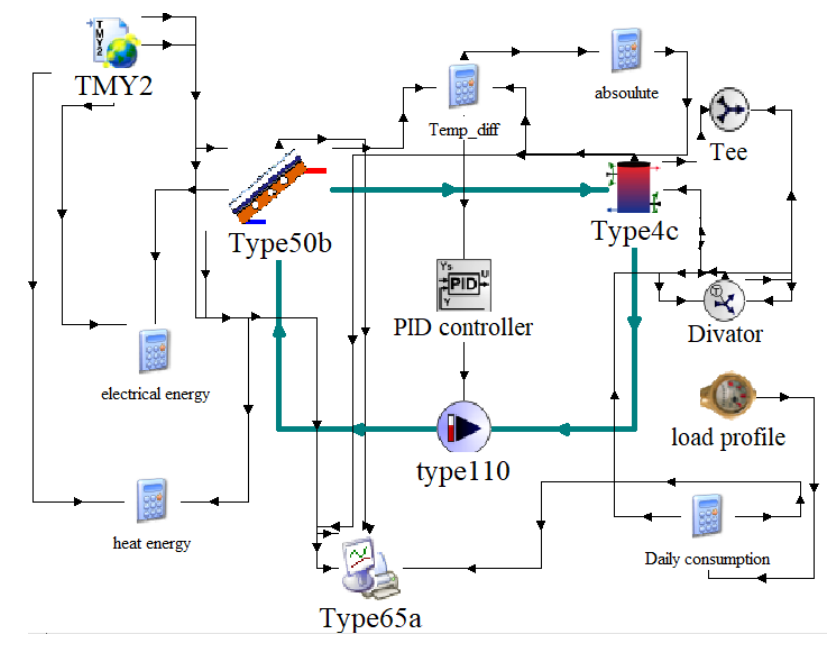

Fig. 3. TRNSYS software model.

Each part of the system represents a practical icon in the environment area of the software. TMY2 icon represents the climate source of the model. It depends on which city was used for the simulation process.

Type-50b icon represents the PV/T type used in the recent study which has particular properties for utilizing. The type110 icon represents the bump used for water supply to the $\mathrm{PV} / \mathrm{T}$.

A type-4c icon represents the tank that produces the hot water for consumption. 65a icon represents the online printer for simulation results. In addition to other components that make the simulation in the run mode.

The Stuttgart area does not receive a lot of sunlight in the fall and winter; in reality, the sunlight rarely shines between November and February. However, generally 7 to 7.5 hours of sunlight each day during those months in summer period (Fig. 4).

Opposite, Kabul has ranged from 10 to 12 hours in summer. Kabul has a clear sky, and more sunshine was observed for this city.

Depending on the weather data source, the compression was investigated in TRNSYS. The simulation period used for evaluation for both locations was on June 15, from 05:00 a.m. to $07: 00$ p.m.

The total rate of monthly sunshine hours for locations is illustrated in Fig. 5 for the entire year.

Besides, the solar radiation distribution during that month is also shown in Fig. 6.

The most significant factors in evaluating the two locations are the thermal and electrical behaviors, as illustrated in Fig. 7-8.

Along with the use of PV/T technologies, making the comparision with Stuttgart, it has been observed that Kabul city can be earned higher amount of heat energy; which is more than $50.4 \%$. 


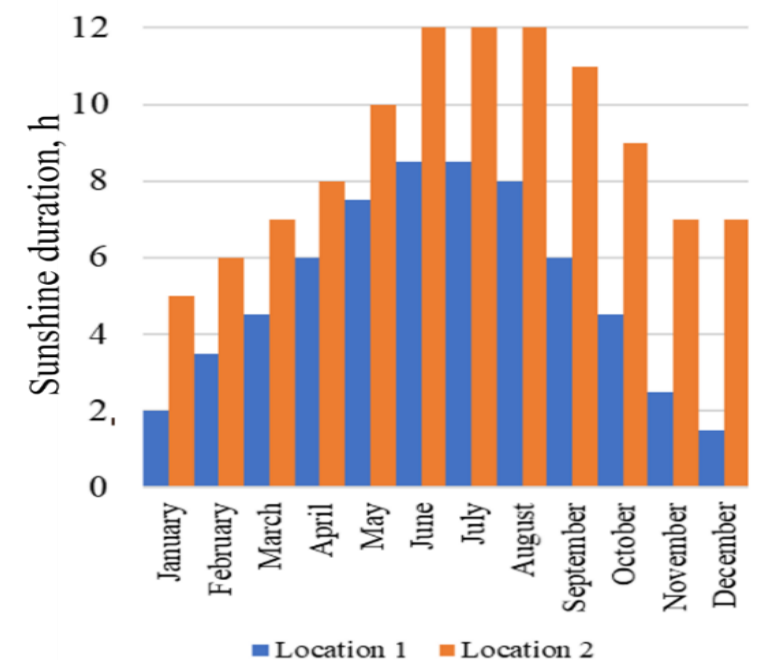

Fig. 4. Monthly average sunshine hours for location1 (Stuttgart) and location 2 (Kabul).

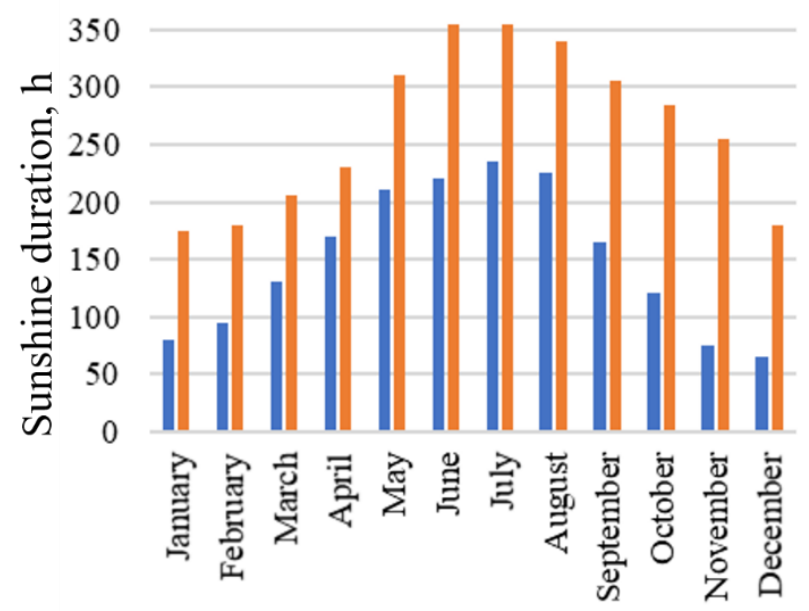

- Location 1 Location 2

Fig. 5. Monthly total sunshine hours for location1 (Stuttgart) and location 2 (Kabul).

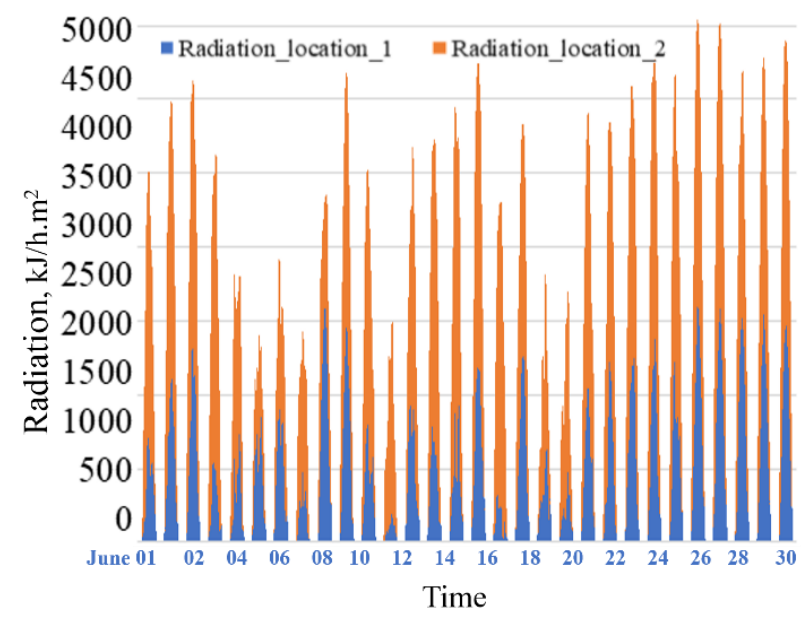

Fig. 6. Solar radiation for location 1 (Stuttgart) and location 2 (Kabul).

Furthermore, the electrical productivity of Kabul has a higher amount by $48.3 \%$ compared to Stuttgart.

At the same time we have to keep in our mind the fact, the annual radiation of Kabul is more than Stuttgart city by $49.12 \%$.

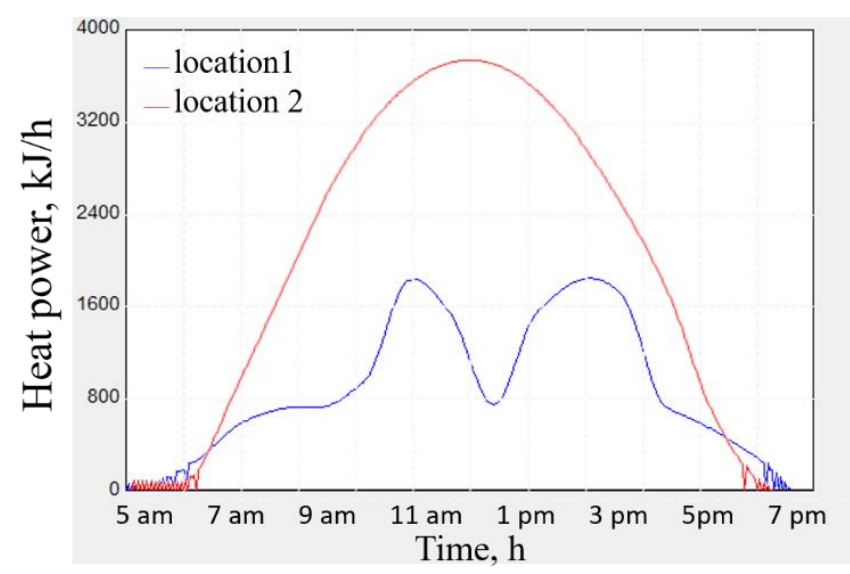

Fig. 7. Heat power for location 1 (Stuttgart) and location 2 (Kabul).

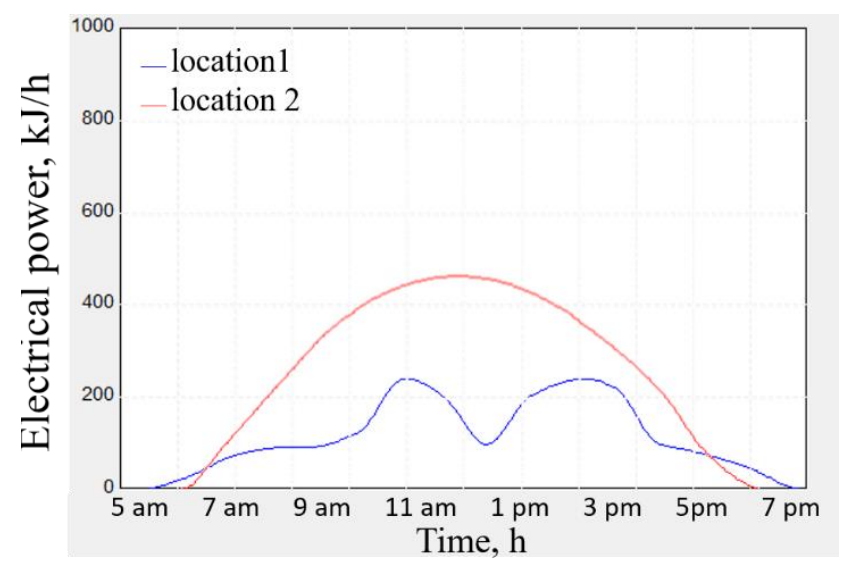

Fig. 8. Electrical power for location 1 (Stuttgart) and location 2 (Kabul).

\section{CONCLUSIONS}

Theoretical work was carried out in this paper describing the performance analysis of a water-cooled hybrid solar collector with a flat-plate absorber. A comparison study was done in the TRNSYS environment for two different weather data sources based on heat and mass transfer calculations use.

It has been realised that that the TRNSYS software is a practical tool to study a PV/T system performance because of its predictability and the potential to create a model.

The testing was conducted under different meteorological conditions choosing Kabul and Stuttgart cities located another continents.

According to what has been conducted in this study, in Kabul more than $50.4 \%$ higher heat energy can be collected than in Stuttgart. Furthermore, Kabul's electrical efficiency is $48.3 \%$ higher than Stuttgart's. Besides, the annual radiation of Kabul is more than Stuttgart city by $49.12 \%$.

The last percentage means that Kabul city seems to be more efficient than Stuttgart in the heat and electrical productivities in PV/T technology for residential applications by the same percentage.

\section{ACKNOWLEDGEMENT}

This work was supported by the Stipendium Hungarian Program and by the Doctoral School of Mechanical Engineering, Institute of Technology, the Hungarian University of Agriculture and Life Sciences, Gödöllö, Hungary. 


\section{REFERENCES}

[1] S. A. Kalogirou, Solar Energy Engineering Processes and Systems, 2nd ed. Elsevier, 2014.

[2] S. Bődi, P. Víg, and I. Farkas, "Possibilities of improving PV/T system efficiency," Hungarian Agriculture Engineering, vol. 7410, no. 33, pp. $55-58,2018$

[3] V. Badescu, P. T. Landsberg, and A. De Vos, "Statistical thermodynamic foundation for photovoltaic and photothermal conversion III: Application to hybrid solar converters," Journal of applied physics, vol. 81, no. 8, pp. 3692-3699, 1997.

[4] H. P. Garg and R. S. Adhikari, "Conventional hybrid photovoltaic/thermal (PV/T) air heating collectors: Steady-state simulation," Renewable Energy, vol. 11, no. 3, pp. 363-385, 1997.

[5] A. Tiwari and M. S. Sodha, "Parametric study of various configurations of hybrid PV/thermal air collector: Experimental validation of theoretical model," Solar Energy Materials and Solar Cells, vol. 91, no. 1, pp. 17-28, 2007.

[6] A. Kumar, P. Baredar, and U. Qureshi, "Historical and recent development of photovoltaic thermal (PVT) technologies," Renewable and Sustainable Energy Reviews, vol. 42, pp. 1428-1436, 2015.

[7] A. M. Elbreki et al., "The role of climatic-design-operational parameters on combined PV/T collector performance: A critical review," Renewable and Sustainable Energy Reviews, vol. 57, pp. 602647, 2016.

[8] A. M. A. Alshibil, P. VÍG, and I. Farkas, "Transient simulation of a hybrid solar collector system," Mechanical Engineering Letter Szent István University, vol. 20, p. 101, 2020.

[9] S. Dubey, G. S. Sandhu, and G. N. Tiwari, "Analytical expression for electrical efficiency of PV/T hybrid air collector," Applid Energy, vol. 86, no. 5, pp. 697-705, 2009.

[10] A. S. Joshi, A. Tiwari, G. N. Tiwari, I. Dincer, and B. V. Reddy, "Performance evaluation of a hybrid photovoltaic thermal (PV/T) (glass-to-glass) system," International Journal of Thermal Sciences, vol. 48, no. 1, pp. 154-164, 2009.

[11] R. Kumar and M. A. Rosen, "Performance evaluation of a double pass PV/T solar air heater with and without fins," Applied Thermal Engineering, vol. 31, no. 8-9, pp. 1402-1410, 2011.

[12] F. Lucas, J. P. N. Torres, C. A. F. Fernandes, and R. A. M. Lameirinhas, "Renewable Generation Electric System," European Journal of Energy Research, vol. 1, no. 1, pp. 1-6, 2021. 